\title{
Selection of the Most Discriminating Morphological Qualitative Variables for Characterization of Fig Germplasm
}

\author{
Esther Giraldo \\ Department of Vegetables, Dirección General de Innovación y Competitividad Empresarial, Instituto \\ Tecnológico Agroalimentario (INTAEX), Carretera San Vicente, s/n, Apartado 20107, 06071 \\ Badajoz, Spain
Margarita López-Corrales
Department of Hortofruticulture, Centro de Investigación “Finca La Orden-Valdesequera," 06187 Guadajira, Badajoz, Spain

\begin{abstract}
José Ignacio Hormaza ${ }^{1}$
Instituto de Hortofruticultura Subtropical y Mediterránea "La Mayora," Universidad de MálagaConsejo Superior de Investigaciones Científicas (IHSM-UMA-CSIC), Estación Experimental "La Mayora," 29760 Algarrobo-Costa, Málaga, Spain
\end{abstract}

\begin{abstract}
Additional IndeX words. Ficus, genetic resources, management, principal component analysis
Abstract. Most descriptor lists for the characterization of genetic resources in plants include a large number of traits whose evaluation is a lengthy and expensive process making the characterization of large germplasm collections difficult. Consequently, to facilitate the study and the conservation of germplasm, it is important to select carefully the most informative variables for each species. In this work, we applied sequential statistical procedures to select the most discriminant variables in fig (Ficus carica L.) from the initial 134 qualitative variables studied. A total of 34 variables was finally selected and broken down in 97 characters that were grouped by principal component analysis in 11 principal components that explain $93.34 \%$ of the total variability. The unweighted pair group method with arithmetic mean dendrogram derived from a similarity matrix generated using the Pearson's correlation coefficient among the 11 principal components selected classifies the cultivars in four main groups mainly based in the production type. These results show that redundant information can be obtained in morphological studies with a large number of variables resulting from correlation between variables. Consequently, a carefully selected and reduced number of highly discriminating variables can allow efficient fig germplasm characterization and discrimination resulting in significant savings of time and resources.
\end{abstract}

The common fig is a gynodioecious woody perennial species with two tree types: the inedible caprifig, which is functionally a male fig that produces syconia with both male and short-styled female flowers, and the female trees that produce syconia with only female flowers that will develop into the edible seeded figs (syconia with multiple one-seed fruit) (Stover et al., 2007; Valdeyron and Lloyd, 1979). Three different types of female figs can be distinguished depending on the cropping/pollination characteristics, common type, Smyrna, and San Pedro (Stover et al., 2007). Most of the fig genotypes are the common type that produces parthenocarpic fruit without pollination; commontype figs are able to produce one (unifera types) or two crops (bifera types). The Smyrna type requires pollination with pollen from caprifigs (caprification) for fruit development to occur. Finally, the San Pedro type can produce two crops; the first crop (brebas) is parthenocarpic and the second crop (figs) is produced only after pollination.

Figs seem to have been part of food production in the Mediterranean basin since the end of the early Bronze Age,

Received for publication 8 Jan. 2010. Accepted for publication 12 Apr. 2010. Financial support for this research was provided by the Spanish Ministry of Education-FEDER (project grants RFP 2004-00007, RF2007-00023, and AGL2007-60130/AGR).

${ }^{1}$ Corresponding author. E-mail: ihormaza@eelm.csic.es. providing fresh fruit in summer and storable, sugar-rich, dry figs during the whole year (Zohary and Spiegel-Roy, 1975). In fact, the fig is considered the first domesticated plant of the Neolithic Revolution some 11,000 years ago (Kislev et al., 2006), probably as a result of the simplicity of its vegetative propagation through cuttings.

In Spain, cultivated, wild and feral fig trees are found in most areas of the country. However, fig remains mostly as a traditional crop and, like in other Mediterranean countries, important genetic erosion is taking place as a result of biotic and abiotic processes (urbanization, extension of intensive crops, absence of caprification, water deficit in marginal areas, etc.) (Mars et al., 1998; Salhi-Hannachi et al., 2004). The increasing concerns on reduced levels of genetic diversity in crop species (Esquinas-Alcazar, 2005; Tanksley and McCouch, 1997) have led to the need to preserve as much genetic diversity as possible both in situ and ex situ not only for the long-term survival of the species, but also to have enough variability available for breeding programs. Although several efforts have been carried out to conserve fig genetic resources in germplasm banks (Flaishman et al., 2008; Giraldo et al., 2008a; Stover and Aradhya, 2008), appropriate management of the germplasm collections requires defining patterns of phenotypic variability within the collections and to select the most significant variables to establish strategies for better conservation and use of 
genetic resources. For this purpose, the analysis of genetic diversity in germplasm collections facilitates reliable classification of the accessions conserved and the identification of subsets or core accessions with possible use for specific breeding purposes (Escribano et al., 2008; Mohammadi and Prasanna, 2003).

Despite the advances in molecular characterization in fig (Achtak et al., 2009; Giraldo et al., 2005, 2008a; Ikegami et al., 2009; Khadari et al., 2005), phenotypic characterization is always needed and it should be included in any program of conservation and use of genetic resources (Giraldo et al., 2008b). Ideally, this characterization should be made under the same edaphoclimatic conditions. However, morphological characterization is a complex process and, to optimize it, descriptor lists for a high number of species have been developed. In fig, a group of international experts developed and published a list of descriptors (International Plant Genetic Resources Institute and Centre International de Hautes Etudes Agronomiques Méditerranéennes, 2003) with the aim of facilitating the characterization process in this species. However, the analyses of morphological traits in fig are even more complex than in most fruit tree species as a result of some particular characteristics of this species such as the frequent production of two different crops (breba and main crop), the presence of four different types of leaves, or its complex floral biology. Consequently, the current descriptors list available has a total of 192 traits from which 126 are qualitative and 66 are quantitative. This high number of traits and the need to replicate observations during at least 2 years makes phenotypic characterization in this species a slow and time- and resourceconsuming process, especially in developing countries with scarce economic resources.

Thus, to optimize the qualitative morphological characterization of fig cultivars, in this work, we analyzed a set of qualitative traits with the objective of selecting the most discriminant traits that should be prioritized for future studies in the different germplasm collections of this species. The approach followed in this work can be also useful to optimize phenotypic characterization in other woody plant species.

\section{Materials and Methods}

Plant material. Observations were made in 35 fig accessions conserved in the fig germplasm collection in the Finca La Orden-Valdesequera in Badajoz, Spain (Table 1). Those accessions were selected among those available in our collection base at two selection criteria: they should be at least 10 years old at the time of analysis and at least three trees with uniform growth should be represented for each accession. Three trees were evaluated from each accession and data were taken during three consecutive biological cycles (2001 to 2004) to minimize environmental effects.

Traits Evaluated. A total of 134 qualitative variables were studied; 91 of them were described by the International Plant Genetic Resources Institute and Centre International de Hautes Etudes Agronomiques Méditerranéennes (2003) and 43 are new variables not included previously but, according to our observations, could be of interest for fig characterization (Table 2). The variables studied include two biological variables, 21 vegetative variables, 36 breba crop variables, 36 fig crop variables, 14 three-lobed leaf variables, 14 five-lobed leaf variables, and 11 entire leaf variables (Table 2).
Table 1. Fig accessions analyzed in this work to select the most discriminant variables with their reported origin.

\begin{tabular}{rll}
\hline No. & \multicolumn{1}{c}{ Accession } & \multicolumn{1}{c}{ Reported origin } \\
\hline 1 & Alacantina & Balearic Islands, Spain \\
2 & Albatera & Valencian Community, Spain \\
3 & Arail & Andalusia, Spain \\
4 & Blanca Albondón & Andalusia, Spain \\
5 & Blanca Valenciana & Andalusia, Spain \\
6 & Blava & Balearic Islands, Spain \\
7 & Bota Morada & Castile and Leon, Spain \\
8 & Boyuna & Extremadura, Spain \\
9 & Calabacita R & Catalonia, Spain \\
10 & Colar Elche & Valencian Community, Spain \\
11 & Cuello Dama Negro & Valencian Community, Spain \\
12 & Franciscana & Castile-La Mancha, Spain \\
13 & Goen & Extremadura, Spain \\
14 & Gota La Miel & Valencian Community, Spain \\
15 & Hoñigal & Extremadura, Spain \\
16 & Kadota & USA \\
17 & Lampa Preta & Portugal \\
18 & Lampaga & Andalusia, Spain \\
19 & Mare de Deu & Balearic Islands, Spain \\
20 & Martinenca Mina & Balearic Islands, Spain \\
21 & Moscatel & Castile-La Mancha, Spain \\
22 & Nazaret & Israel \\
23 & Negra Cabezuela & Extremadura, Spain \\
24 & Negra Calabacilla & Andalusia, Spain \\
25 & Negra Común & Andalusia, Spain \\
26 & Negra Pozuelo & Andalusia, Spain \\
27 & Pacueca & Andalusia, Spain \\
28 & Pezonuda & Andalusia, Spain \\
29 & Picholetera & Extremadura, Spain \\
30 & Roja Almohadín & Castile-La Mancha, Spain \\
31 & San Joao Branco & Portugal \\
32 & Tocal & Andalusia, Spain \\
33 & Verde Pozuelo & Andalusia, Spain \\
34 & Verdejuela & Extremadura, Spain \\
35 & Verdejo & Extremadura, Spain \\
\hline & &
\end{tabular}

To determine the variable "rooting ability of the cuttings," a trial with 10 cuttings/cultivar was made in the nursery. To study the leaf variables, 20 fully developed leaves localized in the middle third of the shoot were collected from each tree $(10+10$ for the two predominant shapes). Leaves of 10 random shoots/tree were counted to evaluate the variables "number of leaves per shoot" and "leaf shape." To evaluate the fruit variables, 20 fruit/tree ( 20 of the breba crop and 20 of the main crop, 10 to determine morphological variables, and 10 for organoleptic variables) and 60 fruit/cultivar (60 of the breba crop and 60 of the main crop) were measured. To evaluate the variables "amount of fruitlets" and "fruitlet size," fruitlets of the longitudinal section of the fruit were counted and measured with a digital caliber. In all cases, color variables were determined using the Royal Horticultural Society Color Chart (Royal Horticultural Society, 2001).

STATISTICAL ANALYSES. The data collected for each variable were codified as present/absent in databases and analyzed statistically using SPSS (Version 12.0; SPSS, Chicago, IL). A new quantitative variable was created for each of the classes of qualitative traits, in which the frequency indicates the presence 
Table 2. List of variables (biological, vegetative, leaf, and fruit) and categories for each variable studied in this work in the 35 fig accesssions listed in Table 1.

\begin{tabular}{|c|c|}
\hline Variable $^{z}$ & Categories \\
\hline \multicolumn{2}{|l|}{ Biological } \\
\hline Crop setting fruit & Bifera, unifera, San Pedro, Smyrna, caprifig \\
\hline Pollination requirement for fruit set & No, yes \\
\hline \multicolumn{2}{|l|}{ Vegetative } \\
\hline Tree growth habit & Erect, semierect, open, spreading, weeping \\
\hline Apical dominancy of seasonal growth & Absent, present, alternate \\
\hline Apical dominancy in the structure of the tree & Absent, present, alternate \\
\hline Relative degree of branching & Sparse, intermediate, dense \\
\hline Lateral shoot formation on seasonal growth & Absent, present \\
\hline Size of the tree & Large, medium, small \\
\hline Terminal bud shape & Conical, spherical, other \\
\hline Terminal bud color in dormancy & Yellow, light green, green, reddish, orange, brown \\
\hline Terminal bud color in activity & Yellow, light green, green, reddish, orange, brown \\
\hline Seasonal shoot color in vegetative resting & Green, grey, orange, brown, light brown \\
\hline Seasonal shoot color in activity & Green, grey, orange, brown, light brown \\
\hline Tendency to form suckers & None, low, medium, high \\
\hline Rooting ability of the cuttings & Low, medium, high \\
\hline Nodal swelling prominency & Absent, soft, intermediate, prominent \\
\hline Nodal swelling location & $\begin{array}{l}\text { Trunk, older branches, young branches, trunk and older branches, trunk, } \\
\text { older branches, and young branches, older and young branches }\end{array}$ \\
\hline Bark tuber quantity & Absent, rare, frequent, abundant \\
\hline Bark tuber shape & Globe, elongate, globe and elongate \\
\hline Bark tuber location & $\begin{array}{l}\text { Trunk, trunk and older branches, trunk, young branches and older } \\
\text { branches, older branches }\end{array}$ \\
\hline Burr knots & Absent, rare, frequent, abundant \\
\hline Leaf shape $(\%)$ & Entire, three lobes, five lobes, \\
\hline Number of leaves per shoot & Rare, intermediate, frequent, abundant \\
\hline
\end{tabular}

Leaf

Shape of central lobe (lobed leaves)

Shape of lobe (entire leaves)

Little lobes in central lobe

Little lobes in lateral lobes (lobed leaves)

Little lobes in sinus (lobed leaves)

Large basal lateral lobes on petiole sinus (lobed leaves)

Shape petiole sinus

Leaf margin

Density of hairs on leaf upper surface

Density of hairs on leaf lower surface

Venation on leaf lower surface

Leaf lower surface color

Leaf upper surface color

Petiole cross-section

Petiole color

Fruit

Fruit shape

\section{Fruit symmetry}

Ostiole opening

Ostiole prominency

Drop at the ostiole

Ostiole cracks
Bifera, unifera, San Pedro, Smyrna, caprifig

Erect, semierect, open, spreading, weeping

Absent, present, alternate

Absent, present, alternate

Absent, present

Large, medium, small

Conical, spherical, other

Yellow, light green, green, reddish, orange, brown

Yellow, light green, green, reddish, orange, brown

None, low, medium, high

Low, medium, high

Absent, soft, intermediate, prominent

runk, older branches, young branches, trunk and older branches, trunk, older branches, and young branches, older and young branches

Absent, rare, frequent, abundan

Globe, elongate, globe and elongate

and older

Absent, rare, frequent, abundant

Rare, intermediate, frequent, abundant

Spatulate, linear, lyrate, latate

Triangular, asymmetric triangular, cordate, lanceolate, oblong, unilobulated

Absent, rare, intermediate, abundant

Absent, rare, intermediate, abundant

Absent, rare, intermediate, abundant

Absent, in one sinus, in both sinus

Decurrent, truncate, cordate, calcarate, open calcarate

Crenate, serrate, parted, entire, undulate, dentate

None, sparse, intermediate, dense

Unapparent, slightly apparent, apparent

Unapparent, slightly apparent, apparent

Light green, green, dark green, yellow-green

Light green, green, yellow-green

Circular, ovoid, triangular, flattened, ovoid flattened

Light green, green, yellow-green, yellow, brown, light yellow

Spherical, cucurbiform, turbinate, ovoidal, pyriform, spherical-ovoidal, turbinate-pyriform, spherical-turbinate, turbinate-ovoidal, spherical-pyriform, ovoidal-pyriform, cucurbiform-pyriform

Symmetrical, asymmetric

Yes, no

Absent, present

Absent, present

Absent, present 
Table 2. Continued.

\begin{tabular}{|c|c|}
\hline Variable $^{z}$ & Categories \\
\hline Scale color ostiolum & Detached, adhered, semiadhered \\
\hline Scale adhesion ostiolum & Short and thick, variously enlarged, long and slender \\
\hline Shape of the fruit stalk & Short and thick, variously enlarged, long and slender \\
\hline Fruit stalk color & Orange-gray, purple, green, light green, yellow-green, beige, yellow \\
\hline Fruit stalk cross-section & Circular, flattened, rhomboid, triangular \\
\hline Scale of the neck color & Brown, purple, green, light green, yellow-green, beige, yellow \\
\hline Fruit ribs & None, rare, intermediate, abundant \\
\hline Fruit skin cracks & Absent, minute, scanty and longitudinal, abundant and longitudinal \\
\hline Hairs in the fruit skin & None, rare, intermediate, abundant \\
\hline Firmness of the fruit skin & Soft, medium, firm, rubbery \\
\hline Length of style & Short, medium, long \\
\hline Length of the peduncle of the flower & Longer than the flower, similar to the flower, smaller than the flower \\
\hline Presence of male flowers & Absent, present \\
\hline Fruit skin ground color & Black, purple, brown, green, light green, yellow-green, yellow \\
\hline Overcolor: regular band & Absent, black, purple, brown, green, light green, yellow-green, yellow \\
\hline Overcolor: irregular patches & Black, purple, brown, green, light green, yellow-green, yellow \\
\hline Fruit lenticel quantity & Absent, scarce, intermediate, numerous \\
\hline Fruit lenticel color & White, green, beige, pink, yellow, yellow-green, purple, brown \\
\hline Fruit lenticel size & Small, medium, large \\
\hline Pulp internal color & White, amber, pink, red, dark red \\
\hline Pulp cavity & Absent, very small, small, medium, large, very large \\
\hline Amount of fruitlet & None, low, medium, high \\
\hline
\end{tabular}

${ }^{\mathrm{z}}$ Variables included in the fig descriptor list published by International Plant Genetic Resources Institute and Centre International de Hautes Etudes Agronomiques Méditerranéennes (2003) are in bold.

of the observed quality in the individual phenotype. Estimated descriptive tests and contingency tables were obtained for each categorical variable. To calculate phenotypic correlations, the chi square test $\left[\chi^{2}=\sum \sum(\mathrm{nij}-\mathrm{mij})^{2} / \mathrm{mij}\right.$ in which nij $=$ observed frequency and $\mathrm{m}_{\mathrm{ij}}=$ expected frequency (Pearson, 1911)], was estimated. Chi square determines if there is some dependence relation between the variables studied and the cultivar. The contingency coefficient $(C),=\chi^{2} /\left(\chi^{2}+n\right)$, was estimated to assess the degree of relation between the variables studied and the cultivar. $C$ is based on the chi square-corrected statistic, minimizing the effect of the sample size on the quantification of the associated degree. The variables were selected by the standardized contingency coefficient, $C s=$ $C / \sqrt{ }(K-1) / k$ with values of $C s=1, C s>0.75$ or $C s>0.80$ for vegetative, leaf, or fruit variables, respectively. The reason to use different $C$ s values was the different sizes of the samples.

The number of selected variable categories was also reduced by the Pearson correlation coefficient and by principal components analysis (PCA) (Iezzoni and Pritts, 1991). These analyses were performed on the correlation matrix obtained with the frequencies, turning the category variables into quantitative variables (Hagidimitriou et al., 2005; Hair et al., 1995). Those principal components (PCs) with eigenvalues $\geq 1$ were selected according to López and Hidalgo (1994). Relationships among the genotypes studied were estimated using unweighted pair group method with arithmetic mean (UPGMA) cluster analysis based on the similarity matrix developed with the Pearson's coefficients among the 11 PCs selected in this work from the qualitative morphological categories.

\section{Results and Discussion}

CONTINGENCY TABLES AND ESTIMATED DESCRIPTIVE TESTS. Contingence tables and descriptive tests made for each of the variables and cultivars provided a visualization of the frequency distribution of the different categories studied. The cultivars studied showed mainly a semiupright growth habit, a medium size with a dense degree of branching, absence of nodal swellings, abundant bark tubers located in the trunk and in the older branches, absence of burr knots, and high cutting rooting ability. The leaves had mainly five lobes with a latate central lobe and a cordate and calcarate petiole sinus; the number of leaves per shoot ranged from four to nine. Fruit are asymmetric and firm with purple skin, abundant white lenticels, and amber pulp color. Differences were found between the two crops, main and brebas. Thus, the shape of the breba crop was mainly cucurbiform and the shape of the main crop was turbinate meaning that the breba crop shows a longer neck than the main crop. Moreover, the abundance of fruit ribs was intermediate in the breba crop and abundant in the main crop, and the amount and size of fruitless were abundant and larger in size in the breba crop compared with intermediate and small in 
the main crop. Finally, there were also important differences in female flowers between breba and main crops.

Selection of variables USing Contingency ( $C$ ) AND Pearson $\left(\chi^{2}\right)$ Coefficients. A total of 34 quantitative variables were selected by the $C s$ reducing by $74 \%$ the 134 initially studied variables (Table 3). The 175 initial categories corresponding to the 34 selected variables were reduced to 97 categories (Table 3). These results show that most of the variables were broken down in more categories than necessary. Only two or three of the total number of categories for each studied variable depended strongly on the cultivar. Sixteen variables with high $C s$, related with the terminal bud (shape and color), seasonal growth color, and ostiole (aperture, cracks, and scales), showed significant differences among trees and years, probably as a result of variation in environmental conditions during the 3 years of evaluation and/or subjective evaluation. Consequently, those 16 variables were finally discarded.

The variables "regular bands" and "pulp cavity" were selected in the main crop but not in the breba crop. The "pulp cavity" variable in the breba crop presented a Cs of 0.72 that, according to the selection criteria, corresponds to the absence of significant differences among cultivars. However, in the main crop, the $C s$ value was 0.82 that corresponds to significant differences among the cultivars studied. The difference in the $C s$ value between both crops (fig and breba crop) could be the result of differences in the length of time from fruit formation until maturation in each crop, heat stress, or water deficit during the maturation process. Regarding the variable "regular bands," among the cultivars studied, this character was only present in the unifera-type cultivar Calabacita R.

Principal Component anAlysis. The PCA study was used to identify patterns of variability among the 97 selected categories (Iezzoni and Pritts, 1991). PCA for variable number reduction has been widely used in different species (Badenes et al., 1998, 2000; Chatti et al., 2003; Ferriol et al., 2004; Goulão et al., 2001; Hagidimitriou et al., 2005; Martínez-Calvo et al., 2008; PereiraLorenzo et al., 1996, 2003; Pérez-Gonzáles, 1992; Rotondi et al., 2003; Semagn, 2002; Zamora et al., 2003). This study showed that the first 11 PCs contributed $93.3 \%$ of the total variability and the first four PCs explained 79\% of the variability (Table 4).

Table 3. List of the 34 qualitative variables and 97 categories selected in this work after analysis of the 35 fig accesssions listed in Table 1 in base to the standardized contingency coefficient.

\begin{tabular}{|c|c|c|c|}
\hline Variable & IC (no.) $)^{\mathrm{z}}$ & $\mathrm{SC}(\text { no. })^{\mathrm{y}}$ & Selected categories \\
\hline Crop setting fruit & 5 & 5 & Bifera, unifera, San Pedro, Smyrna, caprifig \\
\hline Relative degree of branching & 3 & 3 & Sparse, intermediate, dense \\
\hline Bark tubers shape & 3 & 3 & Globe, elongate, globe and elongate \\
\hline Leaf shape $(\%)$ & 3 & 3 & Entire, three lobes, five lobes \\
\hline Shape of central lobe (three-lobed leaves) & 4 & 3 & Spatulate, lyrate, lanceolate \\
\hline Shape petiole sinus (three-lobed leaves) & 5 & 5 & Decurrent, truncate, cordate, calcarate, open calcarate \\
\hline Shape petiole sinus (five-lobed leaves) & 5 & 4 & Truncate, cordate, calcarate, open calcarate \\
\hline Shape petiole sinus (entire leaves) & 5 & 5 & Decurrent, truncate, cordate, calcarate, open calcarate \\
\hline Petiole color (three-lobed leaves) & 6 & 3 & Light green, yellow, brown \\
\hline Petiole color (five-lobed leaves) & 5 & 3 & Light green, yellow, brown \\
\hline Firmness of the fruit skin figs & 4 & 2 & Soft, firm \\
\hline Firmness of the fruit skin brebas & 4 & 2 & Soft, firm \\
\hline Presence of male flower figs & 2 & 1 & Present \\
\hline Presence of male flower brebas & 2 & 1 & Present \\
\hline Fruit skin ground color figs & 6 & 2 & Black, green \\
\hline Fruit skin ground color brebas & 7 & 2 & Black, green \\
\hline Overcolor: regular band figs & 2 & 1 & Green \\
\hline Overcolor: irregular patches figs & 5 & 3 & Purple, brown, green \\
\hline Overcolor: irregular patches brebas & 7 & 3 & Purple, brown, green \\
\hline Fruit lenticel quantity figs & 4 & 2 & Scarce, intermediate \\
\hline Fruit lenticel quantity brebas & 4 & 2 & Scarce, intermediate \\
\hline
\end{tabular}

${ }^{\mathrm{Z}}$ Initial categories.

${ }^{\mathrm{y}}$ Selected categories. 
Table 5 represents the values obtained for each genotype for each of the four main PCs, whereas Table 6 represents the correlations among the 97 categories of the 34 selected variables explains a higher variability for each of the first four PCs.

Table 4. Eigenvalues and proportion of total variability among the 35 fig cultivars studied explained by the first 11 principal components (PCs) as obtained with principal component analysis.

\begin{tabular}{rccc}
\hline PC & Eigenvalue & Variance $(\%)$ & $\begin{array}{c}\text { Accumulative } \\
\text { variance }(\%)\end{array}$ \\
\hline 1 & 28.35 & 29.23 & 29.23 \\
2 & 24.16 & 24.91 & 54.13 \\
3 & 14.94 & 15.40 & 69.54 \\
4 & 9.54 & 9.84 & 79.37 \\
5 & 2.92 & 3.02 & 82.39 \\
6 & 2.68 & 2.76 & 85.15 \\
7 & 2.17 & 2.24 & 87.39 \\
8 & 1.83 & 1.89 & 89.28 \\
9 & 1.44 & 1.48 & 90.76 \\
10 & 1.33 & 1.37 & 92.13 \\
11 & 1.18 & 1.21 & 93.34 \\
\hline
\end{tabular}

Table 5. Factor loadings of each of the 35 fig cultivars studied for each of the first four principal components (PCs).

\begin{tabular}{llrrrr}
\hline Cultivar & Type & PC 1 & PC 2 & PC 3 & PC 4 \\
\hline Gota la Miel & Bifera & 0.42 & 0.81 & 0.42 & 0.24 \\
Bota Morada & Bifera & 0.32 & 0.92 & 0.46 & 0.20 \\
Nazaret & San Pedro & -1.96 & 0.92 & 0.83 & 0.41 \\
San Joao Branco & Caprifig & -0.55 & -1.18 & 0.18 & -2.94 \\
Lampa Preta & San Pedro & -1.59 & 0.84 & -1.86 & 0.13 \\
Moscatel & Bifera & 0.43 & 0.94 & 0.49 & 0.16 \\
Negra Cabezuela & Bifera & 0.46 & 0.93 & 0.44 & 0.32 \\
Picholetera & Unifera & 0.92 & -1.26 & -2.49 & 0.17 \\
Blanca Albondón & Smyrna & -1.94 & -1.08 & 0.75 & 0.49 \\
Negra Calabacilla & Unifera & -1.95 & -1.03 & 0.64 & 0.49 \\
Blanca Valenciana & Unifera & 0.61 & -1.17 & 0.28 & 0.51 \\
Verde Pozuelo & Unifera & 0.53 & -1.07 & 0.40 & 0.41 \\
Negra Pozuelo & Unifera & 0.56 & -1.10 & 0.36 & 0.60 \\
Calabacita R & Unifera & 0.53 & -1.08 & 0.39 & 0.47 \\
Negra Común & Bifera & 0.46 & 0.87 & 0.41 & 0.28 \\
Lampaga & San Pedro & -1.61 & 0.87 & -1.84 & 0.17 \\
Pezonuda & Unifera & 0.46 & -1.10 & 0.37 & 0.49 \\
Arail & Smyrna & -1.85 & -0.74 & 0.49 & -2.54 \\
Pacueca & San Pedro & -1.61 & 0.88 & -1.83 & 0.17 \\
Verdejo & Bifera & 0.90 & 0.78 & -2.23 & 0.001 \\
Boyuna & Bifera & 0.45 & 0.91 & 0.47 & 0.09 \\
Goen & Bifera & 0.44 & 0.86 & 0.46 & 0.47 \\
Tocal & Caprifig & -1.82 & -1.04 & 0.89 & 0.65 \\
Colar Elche & Bifera & 0.53 & 0.90 & 0.44 & 0.26 \\
Albatera & Bifera & 0.38 & 0.88 & 0.48 & 0.22 \\
Kadota & Bifera & 0.44 & 0.85 & 0.36 & 0.39 \\
Blava & 0.53 & 0.95 & 0.44 & 0.40 \\
Verdejuela & Unifera & 0.53 & -1.04 & 0.31 & 0.62 \\
Hoñigal & Unifera & 0.83 & -1.37 & -2.49 & 0.32 \\
Martinenca Mina & Unifera & 0.55 & -0.87 & 0.16 & -2.69 \\
Franciscana & Unifera & 0.54 & -1.06 & 0.38 & 0.64 \\
Mare de Deu & Unifera & 0.54 & -1.16 & 0.38 & 0.54 \\
Alacantina & Bifera & 0.48 & 0.89 & 0.45 & 0.18 \\
Cuello Dama Negro & Unifera & 0.48 & -0.90 & 0.16 & -2.64 \\
Roja Almohadín & & & &
\end{tabular}

PC1 explains $29 \%$ of the total variability (Table 4) and it is represented by 26 categories that correspond to 11 variables related to figs from parthenocarpic accessions (unifera and bifera type) (Table 6). This component presents a negative correlation with the cultivars of San Pedro, caprifig, and Smyrna types because they do not produce parthenocarpic figs and with 'Negra Calabacilla' considered as unifera but that has very low production of figs (Table 5). PC2 explains $25 \%$ of the total variability (Table 4 ) and it is constituted by 22 categories that correspond to nine variables (Table 6) related to the breba crop, typical characters from cultivars of bifera and San Pedro types (Table 5). This component presents a negative correlation with the unifera $(-0.80)$, caprifig $(-0.18)$, and Smyrna $(-0.15)$ cultivars. The variables "pulp cavity" and "overcolor: regular band" have not been included in breba characterization because no differences for those two variables were found among the accessions studied (Table 6). It is important to note the importance of the qualitative variables related to fruit because the first two PCs explain more than $54 \%$ of the total variability. PC3 explains $15 \%$ of the total variability (Table 4 ) and it is represented by 11 categories corresponding to three qualitative variables related to five-lobed leaves (Table 6). This component presents negative correlations with variables related to entire leaves. PC4 explains $10 \%$ of the total variance (Table 4 ) and it is constituted by 11 categories corresponding to three qualitative variables related to three-lobed leaf variables with a negative correlation with five-lobed and entire leaf variables.

MorPhOLOGICAL VARIABILITY. The UPGMA dendrogram, obtained with $11 \mathrm{PCs}$ and with the 35 fig accessions, is shown in Figure 1. It reflects the similarity among the accessions studied based on measured qualitative variables and shows the discriminative power of the approach followed in this work to classify fig accessions. The accessions are clustered into four main groups mainly based in the production type. Group 2 includes parthenocarpic fig-producing common-type accessions (unifera or bifera accessions with very low production) 'Verde Pozuelo', 'Negra Pozuelo', 'Alacantina', 'Mare de Deu', 'Calabacita R', 'Pezonuda', and 'Hoñigal' with high percentages of three-lobed and five-lobed leaves. This group is divided into two profiles according to the morphology of the leaves and of the main crop. Group 3 includes the San Pedro type accessions 'Nazaret', 'Lampa Preta', 'Lampaga', and 'Pacueca'. Group 4 is constituted by cultivars characterized by the presence of five-lobed leaves with latate central lobe, light green petioles, and with a low percentage of entire leaves and can be divided into two subgroups according to the type of production. Subgroup 4A includes the accessions 'Negra Cabezuela', 'Negra Común', 'Albatera', 'Blava', 'Boyuna', 'Goen', 'Colar Elche', and 'Cuello Dama Negro', which are bifera type and classified according to tree growth habit in the Subgroups 4AA (open growth habit) and 4AB (spreading growth habit). Subgroup 4B includes two Smyrna accessions ('Blanca Albondón' and 'Arail') and 'Negra Calabacilla', a unifera accession with low fig production. Finally, Group 1, unlike the previous groups, includes accessions of different production types (bifera, unifera, and caprifigs). The presence of two caprifig cultivars (Tocal and San Joao Branco) together with parthenocarpic accessions in Group 1B has also been obtained with molecular markers and could indicate a common origin derived from crosses between caprifigs and parthenocarpic accessions (Giraldo et al., 2008a). On the other hand, accessions from the different prospected geographic areas are 
Table 6. Values of the 97 categories of the 34 selected variables for the first four principal components (PCs) in the 35 fig cultivars analyzed listed in Table 1.

\begin{tabular}{|c|c|c|c|c|c|c|c|c|c|}
\hline Variable & PC 1 & PC 2 & PC 3 & PC 4 & Variable & PC 1 & PC 2 & PC 3 & $\overline{\mathrm{PC} 4}$ \\
\hline Crop setting fruit & & & & & Fruit shape figs & & & & \\
\hline Bifera & 0.40 & 0.73 & 0.21 & 0.21 & Spherical & 0.86 & 0.00 & 0.14 & 0.05 \\
\hline Unifera & 0.43 & -0.80 & -0.11 & -0.03 & Cucurbiform & 0.94 & -0.07 & -0.08 & 0.05 \\
\hline San Pedro & -0.62 & 0.32 & -0.43 & 0.08 & Turbinate & 0.86 & 0.22 & 0.19 & 0.01 \\
\hline Smyrna & -0.47 & -0.15 & 0.19 & -0.41 & Ovoidal & 0.90 & 0.12 & 0.18 & 0.00 \\
\hline Caprifig & -0.32 & -0.18 & 0.16 & 0.11 & Pyriform & 0.90 & -0.10 & 0.19 & -0.06 \\
\hline Tree growth habit & & & & & Fruit shape brebas & & & & \\
\hline Semierect & 0.29 & -0.40 & 0.16 & -0.04 & Spherical & 0.07 & 0.95 & -0.01 & -0.03 \\
\hline Open & -0.35 & 0.47 & -0.26 & 0.19 & Cucurbiform & 0.05 & 0.94 & -0.13 & 0.12 \\
\hline Spreading & 0.04 & -0.04 & 0.08 & -0.15 & Turbinate & 0.00 & 0.95 & -0.05 & 0.06 \\
\hline Relative degree of branching & & & & & Ovoidal & 0.03 & 0.97 & -0.02 & 0.10 \\
\hline Sparse & -0.11 & 0.06 & 0.15 & 0.12 & Pyriform & -0.01 & 0.95 & -0.10 & 0.11 \\
\hline Intermediate & 0.02 & -0.22 & 0.40 & 0.03 & Fruit stalk color figs & & & & \\
\hline Dense & 0.05 & 0.18 & -0.48 & -0.09 & Purple & 0.95 & -0.02 & 0.11 & -0.06 \\
\hline Size of the tree & & & & & Beige & 0.89 & 0.09 & 0.15 & 0.10 \\
\hline Large & -0.26 & -0.20 & -0.02 & 0.03 & Fruit stalk color brebas & & & & \\
\hline Small & 0.26 & 0.20 & 0.02 & -0.03 & Purple & -0.03 & 0.95 & -0.13 & 0.05 \\
\hline Bark tuber shape & & & & & Beige & 0.10 & 0.93 & 0.05 & 0.12 \\
\hline Globe & -0.03 & 0.34 & 0.21 & 0.06 & Firmness fruit skin figs & & & & \\
\hline Elongate & 0.25 & -0.20 & -0.04 & 0.16 & Soft & 0.87 & 0.00 & 0.14 & -0.12 \\
\hline Globe and elongate & -0.15 & -0.18 & -0.18 & -0.18 & Firm & 0.90 & 0.06 & 0.12 & 0.11 \\
\hline Leaf shape $(\%)$ & & & & & Firmness fruit skin brebas & & & & \\
\hline Entire & 0.10 & -0.14 & -0.80 & 0.10 & Soft & -0.09 & 0.93 & -0.08 & 0.10 \\
\hline Three lobes & -0.09 & 0.20 & -0.23 & 0.60 & Firm & 0.14 & 0.93 & -0.02 & 0.07 \\
\hline Five lobes & 0.00 & -0.12 & 0.59 & -0.50 & Presence male flower figs & & & & \\
\hline Shape of central lobe: three lobes & & & & & Present & 0.93 & 0.10 & 0.13 & -0.18 \\
\hline Spatulate & -0.01 & 0.02 & -0.04 & 0.96 & Presence male flower brebas & & & & \\
\hline Lyrate & 0.00 & 0.12 & -0.16 & 0.95 & Present & 0.05 & 0.96 & -0.04 & -0.08 \\
\hline Lanceolate & 0.07 & 0.21 & -0.03 & 0.93 & Fruit skin ground color figs & & & & \\
\hline Shape of central lobe: five lobes & & & & & Black & 0.85 & -0.11 & 0.06 & -0.05 \\
\hline Spatulate & 0.10 & -0.21 & 0.84 & -0.40 & Green & 0.81 & 0.16 & 0.17 & 0.05 \\
\hline Linear & 0.07 & -0.09 & 0.97 & -0.04 & Fruit skin ground color brebas & & & & \\
\hline Lyrate & 0.21 & 0.04 & 0.91 & 0.15 & Black & 0.06 & 0.88 & -0.02 & 0.00 \\
\hline Lanceolate & 0.23 & 0.03 & 0.92 & -0.03 & Green & -0.01 & 0.91 & -0.08 & 0.14 \\
\hline Shape of lobe: entire & & & & & Overcolor: regular band figs & & & & \\
\hline Triangular & -0.26 & 0.13 & -0.93 & 0.07 & Green & 0.92 & -0.04 & 0.14 & 0.03 \\
\hline Cordate & -0.04 & -0.05 & -0.97 & 0.07 & Overcolor: irregular patches figs & & & & \\
\hline Unilobulated & -0.18 & 0.08 & -0.97 & 0.07 & Purple & 0.90 & -0.06 & 0.07 & -0.06 \\
\hline Shape petiole sinus: three lobes & & & & & Brown & 0.84 & 0.14 & 0.15 & 0.02 \\
\hline Decurrent & -0.15 & 0.17 & -0.23 & 0.93 & Green & 0.94 & 0.06 & 0.16 & 0.03 \\
\hline Truncate & -0.11 & 0.06 & -0.19 & 0.89 & Overcolor: irregular patches brebas & & & & \\
\hline Cordate & 0.18 & -0.01 & 0.08 & 0.90 & Purple & 0.06 & 0.97 & 0.01 & 0.05 \\
\hline Calcarate & -0.25 & 0.22 & -0.17 & 0.87 & Brown & -0.02 & 0.93 & -0.14 & 0.12 \\
\hline Open calcarate & 0.29 & 0.13 & 0.02 & 0.79 & Green & 0.11 & 0.91 & 0.05 & 0.13 \\
\hline Shape petiole sinus: five lobes & & & & & Fruit lenticel quantity figs & & & & \\
\hline Truncate & 0.12 & -0.18 & 0.90 & -0.19 & Scarce & 0.90 & -0.10 & 0.07 & 0.03 \\
\hline Cordate & 0.17 & -0.10 & 0.91 & 0.03 & Intermediate & 0.93 & 0.13 & 0.15 & -0.04 \\
\hline Calcarate & -0.04 & -0.04 & 0.93 & -0.10 & Fruit lenticels quantity brebas & & & & \\
\hline Open calcarate & 0.31 & 0.08 & 0.84 & -0.03 & Scarce & 0.07 & 0.96 & -0.01 & 0.11 \\
\hline Shape petiole sinus: entire & & & & & Intermediate & 0.00 & 0.97 & -0.09 & 0.06 \\
\hline Decurrent & -0.25 & 0.13 & -0.94 & 0.07 & Fruit lenticels color figs & & & & \\
\hline Truncate & -0.15 & 0.05 & -0.98 & 0.07 & White & 0.91 & 0.07 & 0.11 & -0.08 \\
\hline Cordate & -0.08 & 0.00 & -0.98 & 0.07 & Green & 0.91 & 0.16 & 0.21 & 0.08 \\
\hline Calcarate & -0.23 & 0.11 & -0.95 & 0.07 & Pink & 0.86 & -0.16 & 0.06 & 0.04 \\
\hline Open calcarate & -0.10 & -0.01 & -0.97 & 0.07 & Fruit lenticel color brebas & & & & \\
\hline Petiole color: three lobes & & & & & White & 0.13 & 0.96 & -0.03 & 0.05 \\
\hline Light green & 0.01 & 0.08 & -0.09 & 0.98 & Green & -0.09 & 0.95 & -0.04 & 0.08 \\
\hline
\end{tabular}


Table 6. Continued.

\begin{tabular}{|c|c|c|c|c|c|c|c|c|c|}
\hline Variable & PC 1 & PC 2 & PC 3 & PC 4 & Variable & PC 1 & PC 2 & PC 3 & $\mathrm{PC} 4$ \\
\hline Yellow & 0.02 & 0.16 & -0.10 & 0.94 & Pink & 0.01 & 0.96 & -0.10 & 0.12 \\
\hline Brown & 0.04 & 0.14 & -0.08 & 0.98 & Pulp internal color figs & & & & \\
\hline Petiole color: five lobes & & & & & Amber & 0.89 & 0.05 & 0.15 & 0.11 \\
\hline Light green & 0.18 & -0.07 & 0.96 & -0.09 & Dark red & 0.94 & 0.01 & 0.10 & -0.08 \\
\hline Yellow & 0.12 & -0.05 & 0.96 & -0.04 & Pulp internal color brebas & & & & \\
\hline Brown & 0.17 & -0.04 & 0.97 & -0.06 & Amber & 0.03 & 0.99 & -0.05 & 0.09 \\
\hline Small & 0.94 & 0.00 & 0.11 & 0.14 & & & & & \\
\hline Large & 0.90 & 0.09 & 0.16 & 0.06 & & & & & \\
\hline
\end{tabular}

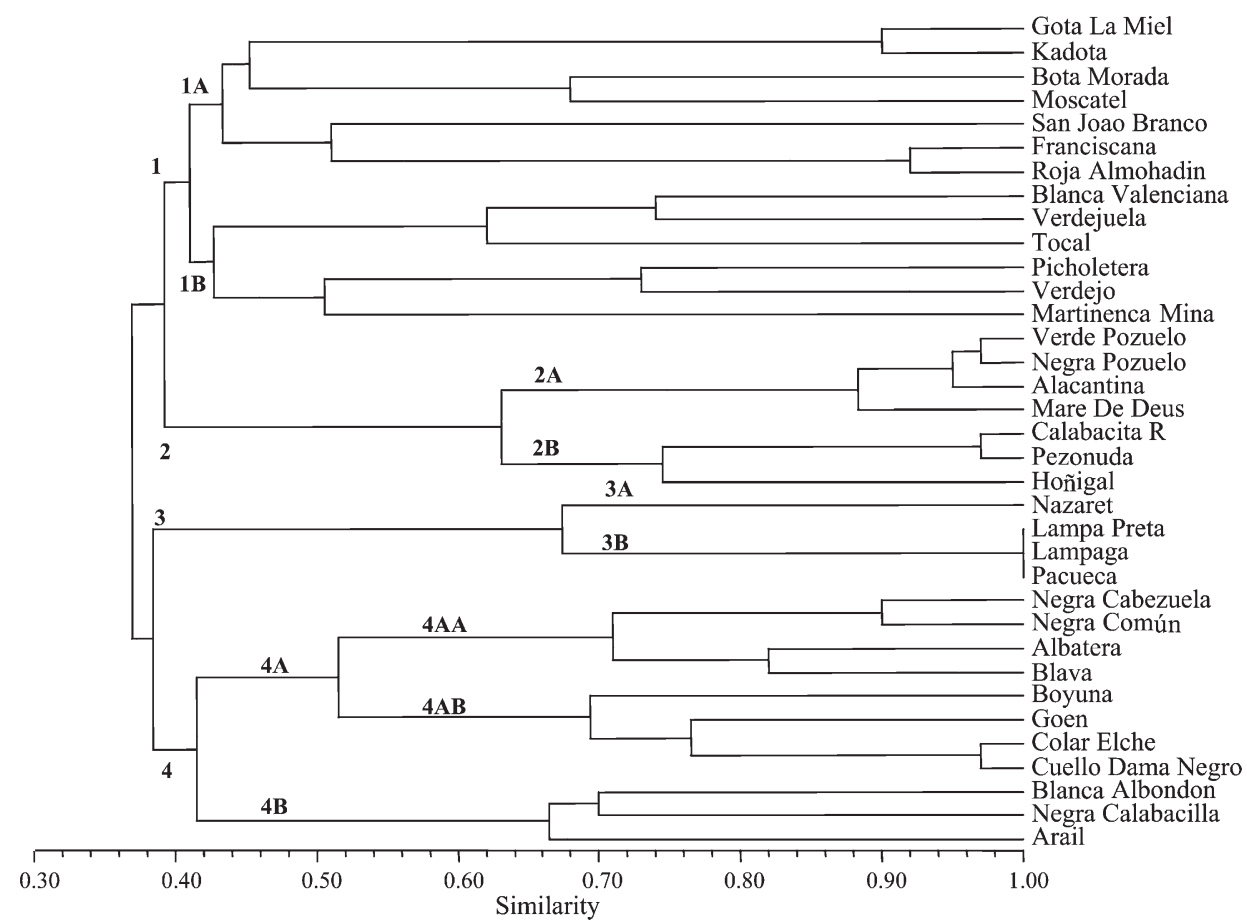

Fig. 1. Unweighted pair group method with arithmetic mean dendrogram of the 35 fig accessions analyzed based on a similarity matrix generated using Pearson's correlation coefficient among the 11 principal components selected in this work.

present scattered in the different groups confirming previous results with molecular markers (Giraldo et al., 2008a) that indicated that geographic origin is not the main criterion for the grouping of fig cultivars. A similar grouping is observed when the accessions are plotted on the first three PCs (Fig. 2). In this case, four groups are observed differentiating unifera, bifera, San Pedro, and caprifigs and Smyrna types.

Similarity values between the different fig accessions ranged from -0.76 ('Calabacita R' and 'Goen') to 0.90 and 1 ('Lampa Preta', 'Lampaga', and 'Pacueca'; 'Colar Elche' and 'Cuello de Dama Negro'; 'Verde Pozuelo', 'Alacantina', and 'Negra Pozuelo'; 'Calabacita R' and 'Pezonuda'; 'Franciscana' and 'Roja Almohadin'; 'Gota la Miel' and 'Kadota' among the indistinguishable morphologically accessions). Previous results with molecular markers on the same set of 35 accessions (Giraldo et al., 2008a) revealed that they corresponded to 27 different genetic profiles. Those results generally coincide with the results obtained in this work in which the cultivars are classified, with a level of similarity of 0.90 , in five groups of two and three undistinguishable accessions. However, in two cases ('Negra Pozuelo' and the group of 'Verde Pozuelo' and 'Alacantina' and 'Calabacita R' and 'Pezonuda'), there were differences in the molecular profiles not reflected in the morphological analyses. In the case of 'Goen', there are morphologic differences with the group formed by 'Colar Elche' and 'Cuello de Dama Negro', although they are indistinguishable using molecular markers; this can be explained by a flood in 1998 that affected the area where the 'Goen' trees are planted.

The approach used in this work (the correlation between variables and cultivars based on trait frequencies and multivariate analysis followed by PCA) has allowed to select a subset of highly discriminant qualitative traits in fig that, in order of importance, are the following: 1) production type: common type (bifera and unifera type), Smyrna, San Pedro, and caprifig type; 2) morphology of the main crop and the breba crop [fruit shape, lenticels color and abundance, skin ground color, overcolor (regular bands and irregular patches), pulp and pulp cavity color, stalk color, skin firmness, and presence of male flowers]; 3) morphology of five-lobed and three-lobed leaves: central lobe shape, petiole sinus shape, petiole color; 4) morphology of entire leaves: leave shape, petiole sinus shape; and 5) tree morphology: tree growth habit, size of the tree, degree of branching, and bark tubers. Most of the variables are related to fruit characteristics (both brebas and figs) highlighting the importance of correct fruit characterization to correctly identify fig accessions.

The selection of highly discriminant variables is important to optimize resources for a feasible morphologic characterization. This is especially important in a crop such as fig with hundreds of genotypes described worldwide in which a high 


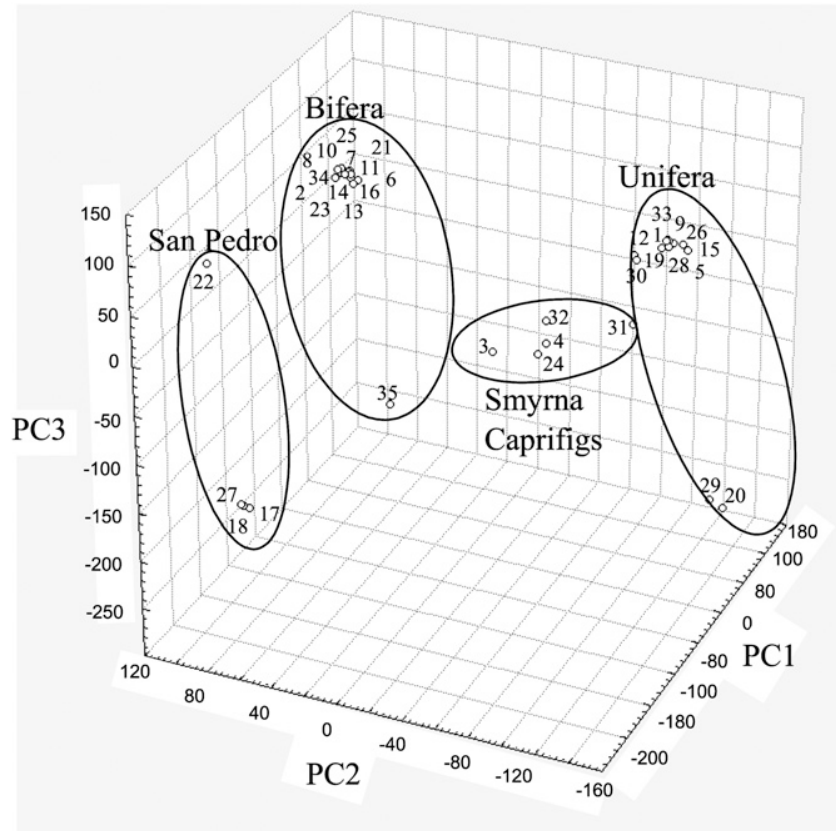

Fig. 2. Three-dimensional diagram of the first three principal components (PC) for the 35 fig accessions analyzed in this work. The numbers in the diagram correspond to the accession numbers in Table 1 .

number of homonymies and synonymies can be observed. Further work to select the most discriminating quantitative variables to classify fig cultivars is needed. Complete qualitative and quantitative morphologic characterization together with molecular characterization will allow optimizing fig germplasm management to distinguish synonyms and homonyms and to study conserved diversity. The approach used in this work can be also useful to select highly discriminant traits in other woody perennial tree species.

\section{Literature Cited}

Achtak, H., A. Oukabli, M. Ater, S. Santoni, F. Kjellberg, and B. Khadari. 2009. Microsatellite markers as reliable tools for fig cultivar identification. J. Amer. Soc. Hort. Sci. 134:624-631.

Badenes, M.L., J. Martinez-Calvo, and G. Llacer. 1998. Analysis of apricot germplasm from the European ecogeographical group. Euphytica 102:93-99.

Badenes, M.L., J. Martinez-Calvo, and G. Llacer. 2000. Analysis of a germplasm collection of loquat (Eriobotrya japonica Lindl.). Euphytica 114:187-194.

Chatti, K., A. Salhi-Hannachi, M. Mars, M. Marrakchi, and M. Trifi. 2003. Analyse de la diversité génétique de cultivars tunisiens de figuier (Ficus carica L.) á láide de caractéres morphologiques. Fruits 59:49-61.

Escribano, P., M.A. Viruel, and J.I. Hormaza. 2008. Comparison of different methods to construct a core germplasm collection in woody perennial species with SSR markers. A case study in cherimoya (Annona cherimola Mill.), an underutilized subtropical fruit tree species. Ann. Appl. Biol. 153:25-32.

Esquinas-Alcazar, J. 2005. Protecting crop genetic diversity for food security: Political, ethical and technical challenges. Nat. Rev. Genet. 6:946-953.

Ferriol, M., B. Pico, and F. Nuez. 2004. Morphological and molecular diversity of a collection of Cucurbita maxima landraces. J. Amer. Soc. Hort. Sci. 129:60-69.

Flaishman, M.A., Z. Yablovich, S. Golobovich, A. Salamon, Y. Cohen, A. Perl, S.D. Yancheva, Z. Kerem, and E. Haklay. 2008.
Molecular breeding in fig (Ficus carica) by the use of genetic transformation. Acta Hort. 798:151-158.

Giraldo, E., M. López-Corrales, and J.I. Hormaza. 2008a. Optimization of the management of an ex-situ germplasm bank in common fig with SSRs. J. Amer. Soc. Hort. Sci. 133:69-77.

Giraldo, E., M. López-Corrales, and J.I. Hormaza. 2008b. Selection of morphological quantitative variables in fig characterization. Acta Hort. 798:103-108.

Giraldo, E., M.A. Viruel, M. López-Corrales, and J.I. Hormaza. 2005. Characterisation and cross-species transferability of microsatellites in the common fig (Ficus carica L.). J. Hort. Sci. Biotechnol. 80:217-224. Goulão, L., T. Valdiviesso, C. Santana, and C.M. Oliveira. 2001. Comparison between phenetic characterisation using RAPD and ISSR markers and phenotypic data of cultivated chestnut (Castanea sativa Mill.). Genet. Resources Crop Evol. 48:329-338.

Hagidimitriou, M., A. Katsiotis, G. Menexes, C. Pontikis, and M. Loukas. 2005. Genetic diversity of major Greek olive cultivars using molecular (AFLPs and RAPDs) markers and morphological traits. J. Amer. Soc. Hort. Sci. 130:211-217.

Hair, J., R. Anderson, R. Tatham, and W. Black. 1995. Multivariate data analysis. 4th Ed. Prentice-Hall, Upper Saddle River, NJ.

Iezzoni, A.F. and M.P. Pritts. 1991. Applications of principal component analysis to horticultural research. HortScience 26:334-338.

Ikegami, H., H. Nogata, K. Hirashima, M. Awamura, and T. Nakahara. 2009. Analysis of genetic diversity among European and Asian fig varieties (Ficus carica L.) using ISSR, RAPD, and SSR markers. Genet. Resources Crop Evol. 56:201-209.

International Plant Genetic Resources Institute and Centre International de Hautes Etudes Agronomiques Méditerranéennes. 2003. Descriptor for fig. IPGRI, Rome, Italy, and CIHEAM, Paris, France. Khadari, B., A. Oukabli, M. Ater, A. Mamouni, J.P. Roger, and F. Kjellberg. 2005. Molecular characterization of Moroccan fig germplasm using intersimple sequence repeat and simple sequence repeat markers to establish a reference collection. HortScience 40:29-32.

Kislev, M.E., A. Hartmann, and O. Bar-Yosef. 2006. Early domesticated fig in the Jordan Valley. Science 312:1372-1374.

López, J.A. and M.D. Hidalgo. 1994. Análisis de componentes principales y análisis factorial, p. 473-503. In: M. Ato and J.J. López (eds.). Fundamentos de estadística con Systat. Addison Wesley Iberoamericana, Madrid, Spain.

Mars, M., T. Chebli, and M. Marrakchi. 1998. Multivariate analysis of fig (Ficus carica L.) germplasm in southern Tunisia. Acta Hort. 480:75-81. Martínez-Calvo, J., A.D. Gisbert, M.C. Alamar, R. Hernandorena, C. Romero, G. Llacer, and M.L. Badenes. 2008. Study of a germplasm collection of loquat (Eriobotrya japonica Lindl.) by multivariate analysis. Genet. Resources Crop Evol. 55:695-703.

Mohammadi, S.A. and B.M. Prasanna. 2003. Analysis of genetic diversity in crop plants - Salient statistical tools and considerations. Crop Sci. 43:1235-1248.

Pearson, K. 1911. On the general theory of the influence of selection on correlation and variation. Biometrica 8:437-443.

Pereira-Lorenzo, S., J. Fernández-López, and J. Moreno-Gonzalez. 1996. Variability and grouping of northwestern Spanish chestnut cultivars (Castanea sativa). I. Morphological traits. J. Amer. Soc. Hort. Sci. 121:183-189.

Pereira-Lorenzo, S., A.M. Ramos-Cabrer, and J. Ascasibar-Errasti. 2003. Analysis of apple germplasm in northwestern Spain. J. Amer. Soc. Hort. Sci. 128:67-84.

Pérez-Gonzáles, S. 1992. Associations among morphological and phenological characters representing apricot germplasm in central Mexico. J. Amer. Soc. Hort. Sci. 117:486-490.

Rotondi, A., M. Magli, C. Ricciolini, and L. Baldoni. 2003. Morphological and molecular analyses for the characterization of a group of Italian olive cultivars. Euphytica 132:129-137.

Royal Horticultural Society. 2001. Royal Horticultural Society Colour Chart. Royal Horticultural Society, London, UK.

Salhi-Hannachi, A., M. Trifi, S. Zehdi, J. Hedfi, M. Mars, A. Rhouma, and M. Marrakchi. 2004. Inter-simple sequence repeat fingerprints to 
assess genetic diversity in Tunisian fig (Ficus carica L.) germplasm. Genet. Resources Crop Evol. 51:269-275.

Semagn, K. 2002. Genetic relationships among ten endod types as revealed by a combination of morphological, RAPD and AFLP markers. Hereditas 137:149-156.

Stover, E. and M. Aradhya. 2008. Fig genetic resources and research at the US national clonal germplasm repository in Davis, California. Acta Hort. 798:57-68.

Stover, E., M. Aradhya, L. Ferguson, and C.H. Crisosto. 2007. The fig: Overview of an ancient fruit. HortScience 42:1083-1087.
Tanksley, S.D. and S.R. McCouch. 1997. Seed banks and molecular maps: Unlocking genetic potential from the wild. Science 277:10631066.

Valdeyron, G. and D.G. Lloyd. 1979. Sex differences and flowering phenology in the common fig (Ficus carica L.). Evolution 33:673-685.

Zamora, A., C. Barboza, J. Lobo, and A.M. Espinoza. 2003. Diversity of native rice (Oryza Poaceae) species of Costa Rica. Genet. Resources Crop Evol. 50:855-870.

Zohary, D. and P. Spiegel-Roy. 1975. Beginnings of fruit growing in old world. Science 187:319-327. 